\title{
INVENTÁRIO DE BENS CULTURAIS DO MUSEU HISTÓRICO DE PRESIDENTE PRUDENTE - SP
}

Mariane Celeste,. Michelle Fernandes, Adriana Hashinaga, Fabrícia Dias da Cunha de Moraes Fernandes Borges

Universidade do Oeste Paulista, Curso de Arquitetura e Urbanismo, Presidente Prudente, SP. E-mail: fabricia.arquiteta@gmail.com

\section{RESUMO}

Nos dias atuais com a globalização e a padronização, perde-se a identidade e o valor histórico de obras arquitetônicas, paulatinamente o sentimento de pertencimento vai se acabando. Contudo a Constituição Federal de 1988, aliada á órgãos de proteção como IPHAN, protegem os edifícios arquitetônicos tornando-os patrimônio histórico cultural. Para que se torne possível preservar um bem cultural é preciso instrumentos de proteção como o tombamento que é um ato administrativo realizado pelo poder público e impede a destruição e descaracterização do bem, e o inventário que é um instrumento de identificação indispensável para a proteção e preservação do patrimônio cultural. Com isso nosso trabalho tem como objetivo produzir um inventário do Museu Histórico da cidade de Presidente Prudente - SP. Coletamos informações sobre o museu histórico através de pesquisas in loco, textos e imagens do museu, assim como revisões bibliográficas.

Palavras-chave: Patrimônio. Globalização. Inventário. Museu. Presidente Prudente - SP.

\section{INVENTORY OF CULTURAL GOODS OF THE HISTORIC MUSEUM OF PRESIDENTE PRUDENTE - SP}

\begin{abstract}
Nowadays with globalization and standardization, it loses the identity and the historical value of architectural works, gradually the feeling of belonging will be over. However, the Federal Constitution of 1988, allied to protection organs as IPHAN, protects the architectural buildings making them historical cultural heritage. So that to be possible to preserve a cultural property is necessary instruments such as the registration which is an administrative act accomplished by the government and prevents the destruction and distortion of good, and the inventory that is an is a necessary identification instrument for the protection and preservation of cultural heritage. Thus our work aims to produce an inventory of Presidente Prudente City Historical Museum - SP. We collect information on the historical museum through research on site, texts, museum images, as literature reviews.
\end{abstract}

Keywords: Heritage. Globalization. Inventory. Museum. Presidente Prudente - SP. 


\section{INTRODUÇÃO}

A preservação de um edifício histórico é uma forma de transmitir à sociedade atual parte da cultura e história que sua comunidade vivenciou em determinada época; é responsável pela preservação da memória coletiva ou até mesmo a criação de uma para as gerações futuras (LEMOS, 1981). Portanto, a retirada ou até mesmo a descaracterização de um edifício que teve uma importância histórica consiste na perda da atmosfera de identidade cultural e resultará em um desequilíbrio, e para evitar tal fato, o tombamento é responsável pela preservação de tais obras, tornando-as patrimônio cultural, que no Decreto de 1937, Art. 10 estabelece como patrimônio:

(...) o conjunto de bens móveis e imóveis existentes no País e cuja conservação seja de interesse público, quer por sua vinculação a fatos memoráveis da história do Brasil, quer por seu excepcional valor arqueológico ou etnográfico, bibliográfico ou artístico. (BRASIL, 1937)

Mais adiante a Constituição complementa a conceituação de patrimônio cultural no Art. 216, especificando os bens em formas de expressão; os modos de criar, fazer e viver; as criações científicas, artísticas e tecnológicas; as obras, objetos, documentos, edificações e demais espaços destinados às manifestações artístico-culturais; os conjuntos urbanos e sítios de valor histórico, paisagístico, artístico, arqueológico, paleontológico, ecológico e científico.

A partir disto, pode-se entender que a União considera a defesa dos patrimônios culturais como parte primordial de uma nação ajustada. Existe dois instrumentos de proteção aos patrimônios culturais; o tombamento ato administrativo realizado pelo poder público, o seu pedido pode ser aberto por qualquer pessoa desde que seja comprovado sua importância e impede a destruição e descaracterização do bem, preservando o bem histórico; e o inventário um instrumento de identificação indispensável para a proteção e preservação do patrimônio cultural que consiste na identificação e registro, pelo poder público, por meio de pesquisa e levantamento das características de determinado bem, adotando-se, para sua execução, critérios técnicos objetivos e fundamentados. Os resultados dos trabalhos de pesquisa para fins de inventário são registrados onde há a descrição do bem cultural, constando informações básicas quanto a sua importância, histórico, características físicas, localização, delimitação, estado de conservação, etc. Os bens tombados somente poderão ser destruídos, deteriorados ou alterados mediante prévia autorização do órgão responsável.

Atualmente nas cidades não há imensa preocupação em preservar tais bens, muitas vezes, por falta de informação, edifícios históricos da região são descaracterizados ou até mesmo 
demolidos, desvanecendo sua identidade e memória, fato inegável, levando-se em consideração que, "as noções de patrimônio cultural mantêm-se vinculadas às de lembrança e de memória uma categoria basal na esfera das ações patrimonialistas, uma vez que os bens culturais são preservados em função dos sentidos que despertam e dos vínculos que mantêm com as identidades culturais" (PELGRINI, 2006, P. 02). Portanto esta pesquisa tem por foco produzir um inventário do Museu Histórico da cidade de Presidente Prudente/SP, afim de analisar e documentar sua importância física e subjetiva para a população.

\section{METODOLOGIA}

A metodologia basea-se numa investigação bibliográfica e se fundamentará numa abordagem qualitativa de pesquisa, utilizando-se como instrumento um levantamento bibliográfico e documental, que segundo Teixeira (2000, p. 137), busca a correlação entre a teoria e os dados, entre o contexto e a ação, a partir da compreensão dos fenômenos por meio de sua descrição e interpretação. Para o trabalho com o estudo do tipo de levantamento bibliográfico ocorrerá inicialmente um levantamento das principais produções no contexto nacional de estudos, considerando a peculiaridade do objeto de estudo.

Desse modo, percebe-se que a pesquisa qualitativa vale-se do método indutivo, segundo o qual parte da observação, da análise dos fatos particulares, dos registros para compor um quadro compreensivo para então constituir a generalização universal, ou seja, a teoria. O processo de indução vale-se do princípio do empirismo, no qual o conhecer é dar significado à realidade (KÖCHE, 1997, p. 62).

\section{DESENVOLVIMENTO}

A cidade de Presidente Prudente possui uma extensa história, e obras como o Museu e Arquivo Histórico Prefeito Antônio Sandoval Netto (Figura 1) são provas físicas deste passado.

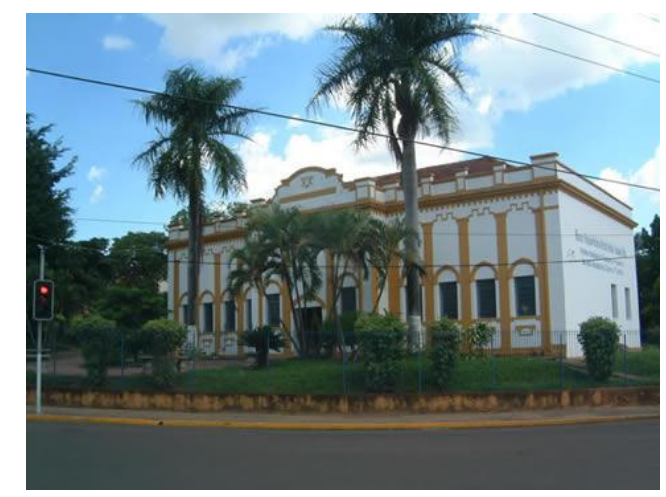

Figura 01. Fachada principal do Museu Hist. de Presidente Prudente.

Fonte: Acervo da equipe, 2015. 
Situado na Av. Manoel Goulart, 2415 - Vila Santa Helena com Rua João Gonçalves Foz, 2179 - Jardim das Rosas. Pres. Prudente - SP, o museu está em um dos pontos mais movimentados da cidade; próximo à unidades estudantis como a Unesp, Senac e Senai, bem como ao lado do maior shopping da região; com um intenso fluxo de pessoas este prédio público tem grande potencial para se tornar um dos pontos mais visitados da cidade.

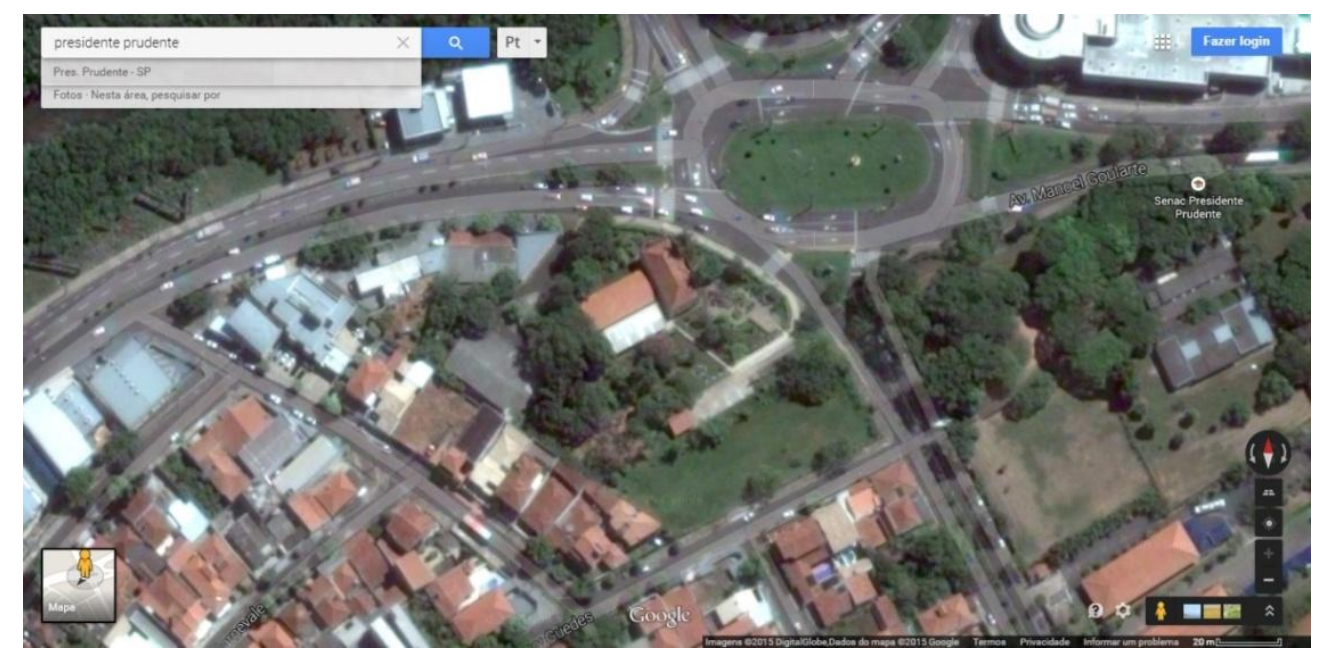

Figura 2. Implantação

Fonte: Imagem retirada do Google Earth, acesso em 27.05.2015.

Sua função inicial foi o de Matadouro Municipal, construído em 1929 pelo Dr. Romeu Leão Cavalcanti, com o objetivo de melhorar as condições de saúde pública, realizando os abates num local higiênico e de fácil distribuição de carne aos moradores de Presidente Prudente.

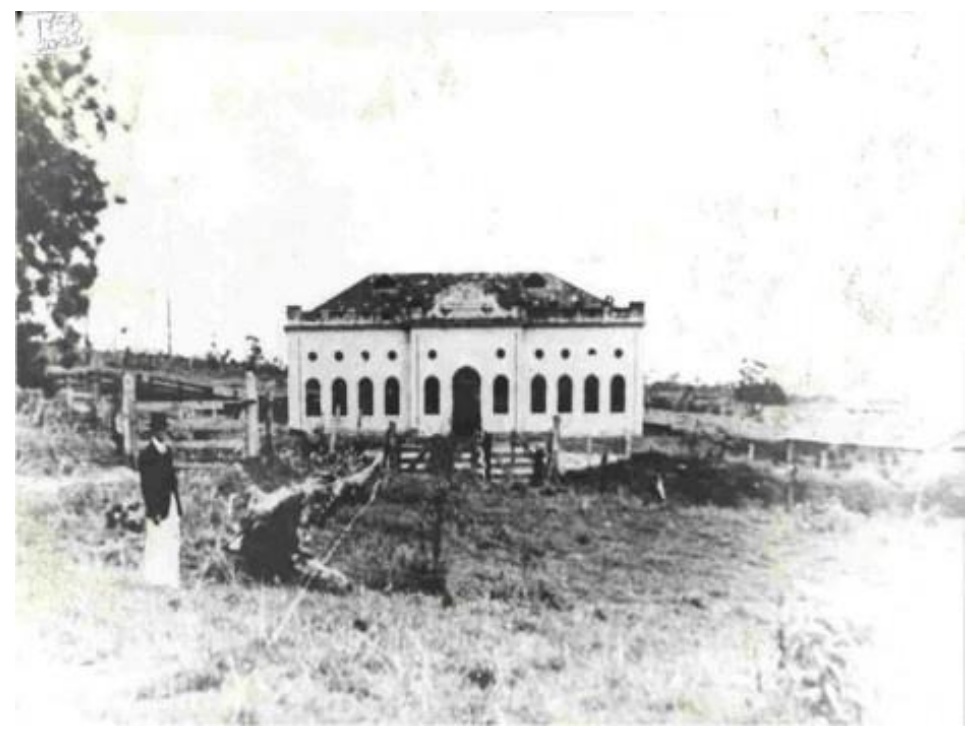

Figura 3. Matadouro na década de 60.

Fonte: Acervo Museu Histórico e Arquivo Municipal. 
Após cessadas suas atividades, sem uso, foi arrendado á empresas da época, até então ser descoberto pela comissão de Instalação e Organização do Museu Municipal, em 1974, iniciando-se assim a negociação de sua doação para sede da entidade, e após a concessão, o edifício sofreu novas adaptações e ampliações, a fim de atender as necessidades para a instalação do museu; ornamentos na fachada principal foram agregados e no interior foi feita uma pintura de paisagem que ocupa uma parede inteira do salão principal, não se tendo conhecimento da autoria de nenhuma destas alterações.

Nos anos 80 duas construções foram anexadas ao edifício principal (1), uma delas para abrigar o acervo documental, instrumental e fotográfico e o outra destinado ao setor administrativo. Sendo assim, atualmente o museu é composto por três volumes retangulares (RESENDE, 1992).

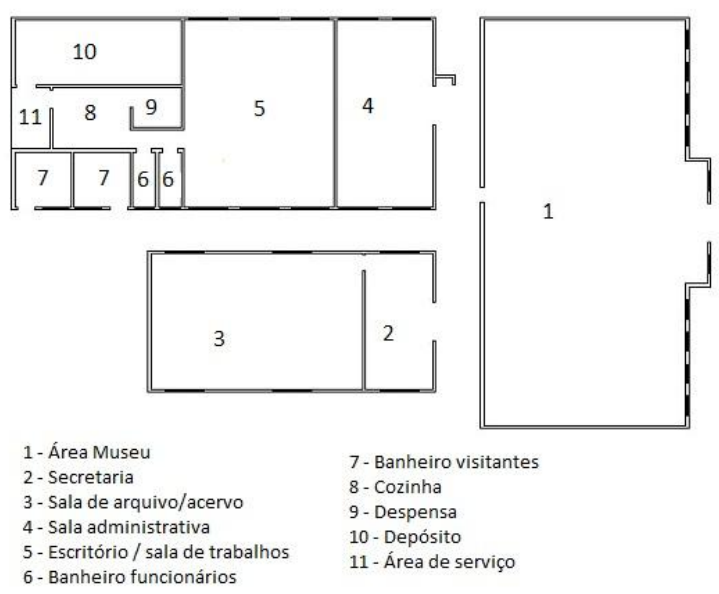

\section{Figura 4}

Fonte: Acero da equipe, 2015

Sendo o volume principal (1) o da fachada, foi também o primeiro a ser construído, os outros dois anexos situam-se atrás deste, e foram construídos vários anos depois; todos os blocos são térreos; sendo o volume principal de pé direito duplo, já os dois outros anexos com pé direito de $3 \mathrm{~m}$. As paredes externas de todos os blocos são de alvenaria, de cores brancas, sendo os pilares aparentes e os da fachada principal são pintados de amarelo e com poucos ornamentos. Internamente todas as paredes são de alvenaria, pintadas de brancas e o chão de revestimento cerâmico de cor escura, apenas na cozinha e nos banheiros de um dos blocos possui as paredes e o piso revestidos em azulejo branco. Na parte externa existe piso tátil percorrendo todas as passagens. As esquadrias são de ferro, pintadas de azul, sua abertura é do modelo Maximo-ar; a cobertura do edifício é de quatro águas com telhas de fibrocimento e platibanda ornamentada. A planta baixa do bloco principal é racional, simétrica, retangular, enquanto nos demais, assimétrica. 
O acesso principal se da pela Área do Museu, já os outros blocos possuem áreas comuns e restritas, como por exemplo o acervo.

Ao analisar o perfil arquitetônico, o estado do edifício e considerando sua data de fundação, pode-se constatar que de forma geral ele está bem conservado, apenas com algumas manchas nas paredes e rachaduras no chão.

Características ecléticas como o frontão, platibanda decorada, ornamentos art decó, bem com aberturas simétricas e pé-direito duplo, caracterizam o museu, criadas de forma á atender as necessidades de iluminação e ventilação natural, características condizentes com a função do prédio e com o clima local; um frontão recortado, evidencia o acesso principal do edifício, a sala de exposições. (BRUAND, 1991)

De fato, as diversas mudanças que foram sendo feitas ao longo da história da edificação valeram-se de uma mão-de-obra inábil, que fez um sistema construtivo simplório, com poucos detalhes, porém grande adequação ás características da região, e provavelmente reforçando-se assim como símbolo de pertencimento para os prudentinos.

\section{CONCLUSÃO}

O pertencimento de patrimônios culturais é responsável por preservar a memória coletiva de uma sociedade, ou seja, conservar sentimentos que foram gerados por um determinado lugar, e o Museu Histórico de Presidente Prudente teve papel relevante para o desenvolvimento da cidade, sendo assim, uma construção que, com o passar dos anos, passou a fazer parte da atmosfera local, e mesmo com suas modificações, ainda é um ponto de referência para a cidade, tanto pelo local em que está inserido quanto pela sua importância histórica.

De modo geral a construção está conservada e bem cuidada, mas seu potencial de atratividade deixa á desejar, visto que ao abordar poucos transeuntes que cruzam as ruas do museu percebe-se que a maioria afirma nunca ter entrado para conhecer as dependências, entretanto, todos afirmam saber que se trata de um museu, e isso mostra que de certa forma, o edifício chame atenção, mas sua influência fica restrita á conhecimentos geográficos e não á crescimento cultural; a fachada é pouco atrativa e encoberta pela vegetação, eventos e mostras poderiam ser realizados, como exibições de filmes para a população, eventos noturnos ou mostras de coleções diferenciadas, o fato é de que o local tem uma geografia privilegiada, estando no caminho diário de diversos pedestres e motoristas, e instigar a curiosidade destes é a forma de alavancar o numero de visitantes. 
Através de seu valor histórico como patrimônio, este conjunto arquitetônico faz-se relevante como referencial urbano, constituindo-se então como elemento fundamental da identidade da cidade. As influências ecléticas que o edifício apresenta foram adaptadas à realidade local; contando com um sistema construtivo simples, o Museu hoje não apenas abriga a história, mas também é um resquício físico da história construtiva de Presidente Prudente.

\section{REFERÊNCIAS}

BRUAND, Y. Arquitetura Contemporânea no Brasil. São Paulo, Perspectiva, 1991.

HIRAO. H., Neres. R.M. O Museu Histórico e Arquivo Municipal de Presidente Prudente - SP. Patrimônio, projeto e identidade na cidade contemporânea. Revista Vitruvius. Presidente Prudente. Jul.2011. Disponível em:

<http://www.vitruvius.com.br/revistas/read/arquitextos/12.134/3957>. Acesso em: 28 de maio de 2015.

LEMOS, C. O que é patrimônio histórico. Volume 51 de Primeiros passos. 2 ed. São Paulo: Brasiliense, 1981.

PELGRINO, A. C. S. Cultura e natureza: os desafios das práticas preservacionistas na esfera do patrimônio cultural e ambiental. Rev. Bras. Hist. vol.26 no.51 São Paulo Jan./June 2006.

Disponível em: <http://www.scielo.br/scielo.php?pid=S0102-

01882006000100007\&script=sci_arttext>. Acesso em: 18 de Ago de 2015.

RESENDE, B. Raízes Prudentinas. 1 ed. Presidente Prudente: Do Autor, 1992.

. Secretaria Municipal de Cultura Governo Municipal de Presidente Prudente - SP.

Disponível em: <http://museu.presidenteprudente.sp.gov.br/historia.php>. Acesso em: 28 de maio de 2015. 